\title{
Chronic undernutrition and the young
}

\author{
BY E. OCLOO \\ Sustainable End of Hunger Foundation, PO Box 36, Madina, Accra, Ghana, West Africa
}

The health problems of Africa especially that of malnutrition has been causing concern all over the world. In fact, in most parts of Africa especially in the war-affected areas, the problem has become chronic, for example in Ethiopia and Angola where the wars have been protracted. By merely looking into the eyes or the faces of pregnant women and children the problem becomes obvious. These pregnant women look pale, miserable and weak. The men look and feel weak and apathetic. Children are the worst victims because of their vulnerability. The main causes, amongst other factors, are the scarcity of food and imbalance in the diet. A satisfactory diet in any part of the world should contain adequate quantities of nutrients to provide energy, replenish body tissues and protect the body from diseases. In addition, in childhood and pregnancy, essential nutrients such as protein, calcium and iron are required to cover the extra needs of rapid growth. The quantity and quality of food of any particular group of people will, therefore, affect their well-being.

The need to develop effective and efficient programmes to mitigate the causes and effects of malnutrition, especially among children, cannot be overemphasized. Research has shown that due to malnutrition the mental development of a young child is retarded. There is also the possibility of irreversible damage to vital brain tissues (Jellife, 1969). These effects obviously have implications for future manpower and economic development in countries like Africa (Jellife, 1969). In order to tackle the problem of chronic undernutrition we need to understand some of their causes especially in Africa.

\section{CAUSES OF CHRONIC UNDERNUTRITION}

In order to understand the causes of chronic undernutrition it will be appropriate to recount the development of a child from conception to school age. In many communities, most families cannot afford to purchase enough food to feed the family let alone concentrate on quality foods (animal protein) which are expensive. The average person is more concerned about quantity. Thus, foods which provide bulk (i.e. are more filling) take precedence over quality foods. The result is protein-energy malnutrition which increases the risk of acute and chronic infections (United Nations, 1968). Many African women are undernourished and suffer anaemia together with infectious diseases because of inadequate nutrition and excessive work and, therefore, their ability to cope with pregnancy, childbirth and breast feeding is weakened (World Bank, 1989). Since the child of an undernourished mother may die sooner than expected, the probable result will be an early return to pregnancy, and another birth of a weak child, giving rise to the vicious cycle; maternal malnutrition, infant death and high fertility (World Bank, 1989).

When the weak child is born he or she continues to be malnourished for a number of reasons. First, the family income is low for various reasons and about three-quarters of this income is spent on food, any fall in their income as a result of crop failures, deployment as a result of economic reforms, etc., means sinking into malnutrition 


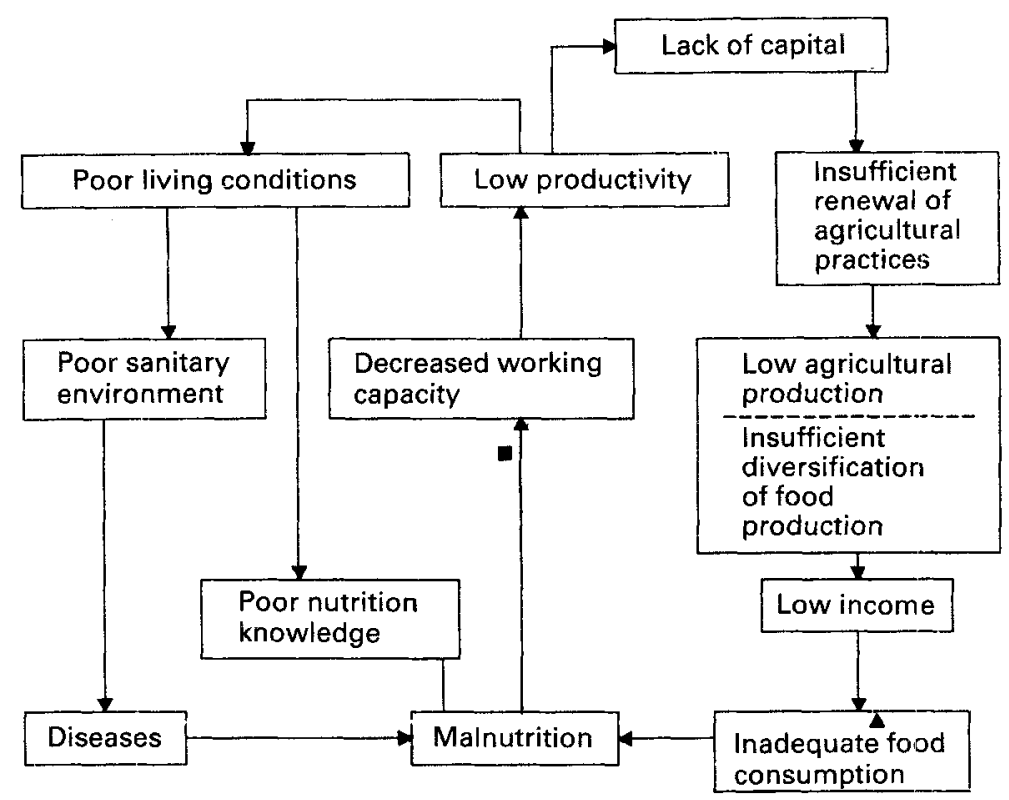

Fig. 1. Vicious cycle of malnutrition. From Food and Agriculture Organization (1982).

(United Nations Children's Fund, unpublished results). This results in poor meal patterns in terms of irregular and inadequate food intake. The required energy is not available to the child in daily meals. In addition lack of personal hygiene in food handling, preparation and storage makes children prone to infectious diseases (Fig. 1).

Children do not receive the attention they need because mothers are engaged in activities directed towards the upkeep of the home. Some of these activities include generating income from farming (growing and selling produce), preparing meals, and collecting fuel and water. The result is that children are left in the care of an older sibling. As a result, the pattern of malnutrition continues up to school age and here again the meal pattern continues to be the same as that described previously. To worsen the situation, at school age children have to help in the activities involved in the upkeep of the family; this means they provide labour on the farms or sell wares either in the market or within the community. The child returns home to help collect fuel and water, which involves long distances. All these activities result in little rest and recreation for the child. Thus, food intake does not relate to energy expenditure.

Cultural practices, beliefs and taboos further compound the situation. Customs, for example, prevent families from adopting balanced and nutritious dietary habits, early introduction and quality of supplementary food for infants, or accepting modern methods of food preparation, processing and preservation. In many communities in Africa, the unchanging traditional patterns of life as they affect roles and food habits are worth noting. In societies where socially defined roles are strictly adhered to, as is the case in many communities in Ghana, men do not assist with household chores and child care. These are seen as entirely the responsibilities of women. With respect to food 
habits certain beliefs and taboos restrict the intake of nutritious foods. For example, one of the predominant beliefs in some communities is that the head of the family, who is usually a man, should have the best portion of the meal. Children, instead, are often given small amounts of meat or fish for fear that giving them a lot will encourage them to steal. With respect to taboos snails and pork are not consumed in certain societies.

Environmental factors such as poor sanitation, degradation of natural resources and seasonal changes also take a toll on the nutritional status of children. Unclean water and the absence of latrines and refuse pits make the population prone to infectious diseases. Soil erosion and depletion of soil fertility, and prolonged drought affect agricultural output. Seasonal changes also affect the nutritional status of the population by affecting food availability and consumption. A classical concept of seasonality in food intake is that people in areas with marked wet and dry seasons show a satisfactory intake after harvesting, usually at the beginning of the dry season, which gradually declines, reaching its lowest ebb during the so-called hungry season (Food and Agriculture Organization, 1982). The Ghana nutrition survey of 1961-2 showed a slowing down in activity or loss of weight during the rainy season from March to September in children of the Northern area and forest zones. A very recent Food and Agriculture Organization (1992) report shows that nearly thirteen million children under 5 years die every year from infection and from hunger, directly or indirectly.

\section{THE EFFECTS OF UNDERNUTRITION}

The quantity and quality of food intake of a person or community to a large extent affects the degree to which that community becomes undernourished. This may result in either (a) normal nutritional status, (b) nutritional diseases by excess and (c) nutritional diseases by deficit (the latter two factors being classified as malnutrition; Food and Agriculture Organization, 1982). In Africa, due to the factors mentioned previously, nutritional diseases by deficit (e.g. kwashiorkor, marasmus, diarrhoea, vomiting, anaemia, vitamin A deficiency, etc.) are more common than those by excess. These deficiencies or diseases cause a weakness of body tissue, reduced resistance to infection or impaired vision and sometimes lead to a stunting of growth in children.

Frequent periods of infection as a result of unhygienic feeding methods result in underweight. Intestinal parasites like hookwork or tapeworm also deplete body nutrients. Furthermore, fever such as that associated with malaria often results in low food intake with its attendant weight losses (Food and Agriculture Organization, 1982). Malnutrition and infection are antagonistic, and together, very often destroy the lives of children. The most vulnerable groups are children (especially from conception to age 5 years), pregnant and lactating women, the sick and convalescent and the elderly (Food and Agriculture Organization, 1982). As mentioned earlier these groups constitute the families of poor farmers, such as agricultural labourers and urban poor who occupy a low socio-economic position. These children go to school tired from doing household chores and are undernourished because of poor meal patterns. The results are physical weakness, lack of stamina for sustained work, lack of initiative, sluggishness and an increased susceptibility to diseases which makes them perform poorly at school. Thus, they grow up with the very problems that their parents have to cope with to survive.

The relationship between normal nutritional status and quality of life especially as it affects the lives of children between 6 and 36 months as shown in research in Tanzania 
indicates that there is an overall linear relationship between nutritional status and mortality, indicating a gradual increase in mortality as nutritional status decreases (Yambi et al. 1991).

The problem of chronic undernutrition and its wider social implications is obvious. As mentioned earlier, there seems to be a direct relationship between the effects on children and the adult population. The growing nutritional deficiencies have greater impact on young children in developing countries where more than one-third die before reaching school age and for those who survive, physical growth and development are impaired (United Nations, 1968).

Even though a complex of factors has been outlined, what comes to mind immediately is the existence of a wide gap between recommended food allowances and food intake. From the available evidence and complex nature of the problem it can be stressed that chronic undernutrition engenders a vicious cycle and, thus, the situation persists, making long-term solutions very difficult.

\section{GHANA'S EXPERIENCES AND INITIATIVES}

In Ghana, government and non-governmental organizations have initiated procedures to educate the population and sensitize them to the causes of and solutions to undernutrition. Some of the education and sensitization programmes include provision of extension services to women to increase food production and effective utilization of protein-rich foods, nutrition education, environmental improvement and rural income generation among the poor. In addition nutritious meals are provided at schools to supplement meals eaten at home; creches have been established in communities to take care of children whose mothers are away working. Credit programmes and special literacy activities have also been instituted by some agencies to enhance women's productivity.

The results of these efforts have been increased awareness amongst women regarding nutrition and family health and gradual reduction in child diseases. However, the problem far from being solved, and much more may have to be done (E. Ocloo, unpublished results).

\section{LESSONS AND RECOMMENDATIONS}

Despite these laudable initiatives a review of some of the lessons will enable us to focus our attention on areas which need to be tackled to reduce chronic undernutrition and produce a long-term solution.

\section{A change in government strategies}

Agricultural programmes and nutritional programme. Very often efforts to increase agricultural production do not relate to the nutritional needs pertaining in the country; however, this is very crucial for the reduction of undernutrition. In the early 1960s, part of the success of nutritional programmes was because, following demonstrations on the use of leafy vegetables and beans in preparing local diets both at domestic and large-scale levels for schools and hospitals, the demand for these vegetables served as an incentive to the farmers to take production of these vegetables more seriously than before. Presently, 
however, the utilization of soya bean is being promoted but there are difficulties in obtaining the beans on a regular basis.

Furthermore, some government policies affect the economic activities of women, and consequently these directly or indirectly affect their children; for example, greater emphasis is placed on cash crop production where men are predominantly involved. Incentives for increased cash crop production are better than those for food crop production. Incentives for increased cash crop production in areas such as pricing, extension services, provision of farm inputs are better than those for food crop production.

The foregoing points render it imperative that a conscious effort be made to ensure that; (1) programmes aimed at increasing agricultural production are linked to programmes to improve household nutrition; (2) governments increase incentives towards food crop production, e.g. provision of credit facilities in terms of inputs to expand production and also storage facilities to reduce post-harvest losses.

Extension programmes. One of the basic problems we have in nutrition education is how to make women understand the problem of malnutrition in the same way that we practitioners perceive it. Most women understand the many factors of the quality of life but, when given a choice, nutritional programmes are not their priority. A greater emphasis is often placed on generating income. Various initiatives have been promoted to meet this need, but one great concern is that an increase in income very often does not result in similar improvement in the nutritional status of children. Cultural practices still prevail irrespective of increased income which is often spent on goods and services not related to direct improvement of the nutritional status of children. It is sad, during visits to some fishing communities in Ghana, to see mothers process and sell fish, yet their children eat food which is high in carbohydrate and extremely low in protein. The concept of nutrition as a priority is still far-fetched. The solution to this problem might lie in participatory educational programmes whereby women and facilitators can analyse the problem together and determine the best course of action.

Increased efforts to reduce post-harvest losses. Despite advances in mechanical grain milling and fuel-efficient stoves, much remains to be done to reduce storage losses (World Bank, 1990). Food and Agriculture Organization data show that about $15-20 \%$ of the cereals produced in Africa are lost through bad storage; for vegetables, storage losses may run as high as $40-50 \%$ (World Bank, 1990). Preservation and storage both at the national and domestic level is needed. Domestic preservation is an area on which it is worth focusing in order to curb undernutrition. Simple processing technologies and packaging materials are needed for domestic food preservation. Some of the indigenous methods of food preservation are carried out under very unhygienic conditions, without any attempt to preserve the nutritional value. Since 1953 efforts have been made to introduce improved and scientific methods of domestic preservation but without much success. Although the women are keen there have been difficulties in getting the right gadgets and packaging materials.

Introduction of appropriate food crops. There is a need to introduce varieties which are easy to utilize. Field experience with the introduction of soya beans and winged bean, for example, indicates that even though these food items are rich in protein they take too much time and effort to process and cook. This has discouraged a lot of women from accepting the idea. Another alternative in enhancing the utilization of such food items would be the establishment of plants to process these food items into a form that can be more easily utilized. 
Improved access to resources for women. Generally the income controlled by women is more likely to be spent on food than that controlled by men. This conclusion is supported by findings from a study conducted in Kenya (Gittinger et al. 1990), which indicated that children from households headed by women were less likely to be moderately or severely malnourished than children from households headed by men, because a greater proportion of incremental household energy was allocated to preschool children. However, because women do not have enough time and energy to farm units of an economic size, they do not generate enough food crops for consumption and sales. It is interesting to note, however, that in some cases where women have been able to increase their income, their nutritional status declined slightly. It was discovered that most of the additional income was generated from very energy-intensive activities, such as weeding, and that the increased expenditure of energy was not compensated by increased energy intake.

In some unusual cases transportation has been found to be an indirect effect on the nutritional status of children. A study on the Iringa District in Tanzania revealed that children were undernourished because women have to walk long distances to collect fuel, therefore, many women cook less often in order to conserve fuel (Gittinger et al. 1990). Several efforts are under way to deal with such problems; for example, in the northern regions of Ghana tricycles with carts are being popularized for carting foodstuffs from farms.

Another crucial factor, as mentioned previously, has been women's access to credit. In Ghana, special credit schemes where non-governmental organizations have assisted women with the required collateral to obtain loans from banks have not had the desired impact because of problems associated with the banks. Some of the banks still request additional collateral; for a number of loan applications the amounts requested are still reduced to an amount with which the women cannot operate efficiently. There have been a number of occasions where loans required for agricultural/seasonal activities, such as rice cultivation and fish processing, either were not provided on time or were never received. The result has been that women who borrowed money from money lenders to start their farming activities with the hope of receiving loans to maintain their farms have now not only lost the little investment they had initially but are also further in debt because they could not afford to pay for labour or buy herbicides to control the weeds. A lot of issues have been raised about problems with special credit schemes, but in order to reduce the incidence of chronic malnutrition we need to address the peculiar problems of women in agricultural production (Gittinger et al. 1990).

\section{SUMMARY AND CONCLUSIONS}

The problem of chronic undernutrition and its direct and indirect effects, especially in Africa are multi-faceted and integrated, and have roots in socio-economic, cultural, environmental, political, technological and other factors. In this scenario, the immediate victims are children, especially those under 5 years of age. There seems to be a vicious cycle of maternal malnutrition, infant death and high fertility as well as malnutrition, ill-health and low agricultural productivity in Africa. These make the situation serious and chronic. It means that the structures which bring about this problem need critical re-evaluation, particularly in terms of increased agricultural productivity, both in quantity and quality, and normal nutritional status. 
Increased production of staple and supplementary foods is now a widespread need in the African continent, as is population control. Experience has shown that nutrition is a complex and interacting phenomenon which is very much influenced by policies that affect socio-economic structures. Since the problem of hunger and malnutrition is a structural problem, nutrition may be regarded as an integral part of development planning. Higher priority may be given, therefore, to food and nutrition planning and their subsequent integration into national development plans, especially by taking into consideration the vulnerable groups which are the children in the population (Idusogie, 1977).

\section{REFERENCES}

Food and Agriculture Organization (1982). Food Nutrition and Agriculture. Guidelines for Agricultural Training Curricula in Africa. FAO Food and Nutrition no. 22, pp. 76-77. Rome: FAO.

Food and Agriculture Organization (1992). Malnutrition in the World. Nutrition the Global Challenge. International Conferences on Nutrition, p. 3. Rome: FAO.

Gittinger, P. J., Chermich, S., Horenstein, N. R. \& Saito, K. (1990). Household Food Security and the Role of Women. World Bank Discussion Papers no. 96. Washington, DC: World Bank.

Idusogie, E. O. (1977). Marriage of Agriculture and Nutrition: and Food and Nutrition Policy for Africa. Joint FAO/WHOIOAU Regional Food and Nutrition Committee for Africa. Regional Office for Africa. Special Paper no. 10. Accra: FAO.

Jellife, D. B. (1969). Child Nutrition in Developing Countries - A Handbook for Fieldworkers. Office of War on Hunger. Agency for International Development, p. 2. Washington, DC: US Department of State.

United Nations (1968). International Action to Avert the Impending Protein Crisis. Feeding the Expanding World Population. Report to the Economic and Social Council of the Advisory Committee on the Application of Science and Technology to Development, pp. 4-5. New York: United Nations.

World Bank (1989). Sub-Sahara Africa - From Crisis to Sustainable Growth. Long Term Perspective Study, p. 75. Washington, DC: World Bank.

Yambi, O., Latham, M. C. \& Habicht, J.-P. (1991). Nutrition status and the risk of mortality in children 6-36 months old in Tanzania. Food and Nutrition Bulletin 13, 271-276. 